\title{
First report of 'Candidatus Phytoplasma asteris' associated with flat stem disease of spinach (Spinacia oleracea L.) in India
}

\author{
Shweta Kumari ${ }^{1} \odot \cdot$ Nagendran Krishnan $^{1} \cdot$ Rajesh Kumar $^{1} \cdot$ Koshlendra Kumar Pandey $^{1} \cdot$ Jagdish Singh $^{1}$. \\ Govind Pratap Rao ${ }^{2}$
}

Received: 24 November 2020 / Accepted: 12 February 2021 / Published online: 30 March 2021

(c) Società Italiana di Patologia Vegetale (S.I.Pa.V.) 2021

Keywords $16 \mathrm{~S}$ rDNA $\cdot$ Vegetable phytoplasma $\cdot$ Leafy vegetable $\cdot i$ PhyClassifier analysis $\cdot$ Nested PCR

During 2019, spinach (Spinacia oleracea L.) belonging to the family Chenopodiaceae (var. All Green) expressing symptoms of flat stem, indicative of phytoplasma infection were observed at the seed production block of the Indian Institute of Vegetable Research (IIVR) farm (Uttar Pradesh, India). The disease incidence ranged from $10-20 \%$. To confirm the phytoplasma presence, total DNA was extracted from the stem tissue of 7 symptomatic samples along with 4 asymptomatic samples. The amplification of ribosomal DNA was done by nested PCR assay with universal primer pairs P1/P7 followed by nested primer pair 3Fwd/ 3Rev (Manimekalai et al. 2010). Semi-nested PCR assay was performed to amplify secA gene using SecAfor $1 / \mathrm{SecArev} 3$ and SecAfor2/SecArev3 primer pairs (Hodgetts et al. 2008). Amplicons of $\sim 1.3 \mathrm{~kb}$ corresponding to $16 \mathrm{~S}$ rDNA region and $\sim 480 \mathrm{bp}$ to $\sec A$ region were yielded only from symptomatic samples. Amplicons were sequenced directly from 3 randomly selected samples. Sequences showed $100 \%$ identity among themselves and were submitted directly to NCBI database (GenBank Accession No. MW137921 and MW139906). Pairwise analysis of 16S rDNA and secA gene indicated maximum identity with two Polish aster yellows phytoplasma strains infecting sugar beet (KU720554, 100\% sequence identity) in different parts of the globe and rapeseed phyllody phytoplasma (CP055264, 99.8\% sequence identity), both belonging to the 16SrI-B phytoplasma sub-group ('Candidatus Phytoplasma asteris'). Further in iPhyClassifier analysis, the virtual RFLP pattern using 17 restriction

Shweta Kumari

sweta.aau@gmail.com

1 ICAR-Indian Institute of Vegetable Research, Uttar Pradesh, Varanasi 22305, India

2 ICAR-Indian Agricultural Research Institute, New

Delhi-110012, Delhi, India enzymes of 16S rDNA gene sequence confirmed the close association of spinach flat stem with 16SrI-B subgroup phytoplasma strain (AP006628) with a similarity coefficient 1.00. Previously, association of $16 \mathrm{SrI}$ subgroup phytoplasma with spinach samples showing yellowing was reported from Iran (Tazehkand et al. 2010). To our knowledge, this is the first report of the 16SrI-B subgroup phytoplasma associated with spinach in India.

\section{Declarations}

Ethical approval The authors declare that they have not used humans and/or animals on their studies.

Conflict of interest Authors declare that they have no conflict of interest.

\section{References}

Hodgetts J, Boonham N, Mumford R, Harrison N, Dickinson M (2008) Phytoplasma phylogenetics based on analysis of sec A and 23S rRNA gene sequences for improved resolution of candidate species of 'Candidatus Phytoplasma.' Int J Syst Evol Microbiol 58:1826-1837

Manimekalai R, Soumya VP, Sathish Kumar R, Selvarajan R, Reddy K, Thomas GV, Sasikala M, Rajeev G, Baranwal VK (2010) Molecular detection of 16SrXI group phytoplasma associated with root (wilt) disease of coconut (Cocos nucifera) in India. Plant Dis $94: 636$

Tazehkand AS, Hosseini Pour A, Heydarnejad J, Massumi H, Azadvar M (2010) Identification of phytoplasmas associated with cultivated and ornamental plants in Kerman province. Iran J Phytopathol 158:713-720 